\title{
Multi-objective global optimization of grillage-type engineering structures using advanced metaheuristics
}

\author{
Rimantas Belevičius, Darius MaČIŪnas, And DmitriJ ŠeŠOK
}

\begin{abstract}
The purpose of the paper is to present the method implemented for a global optimization of grillage-type pile foundations introducing two advanced metaheuristics: AAGA and AGADS. The suggested new optimization algorithm including the synergy of AAGA and AGADS demonstrates improved results comparing with former AGA and GADS. Compromise objective function to be minimized involves the maximum reactive force in piles and maximum bending moment in the connecting beams. The feasibility of a simple weighting technique for the objective function is proved by numerical investigation of objective function domain for several different topologies of foundations. Sizing problem of connecting beams is solved together with the optimization problem. The original finite element program was employed for solution of direct problem.
\end{abstract}

\section{Introduction}

There are many progressive metaheuristic algorithms developed in the world to overcome a wide range of optimization challenges. Usually these algorithms are inspired by a different phenomena in the nature [18]. However not a single optimization algorithm can guarantee the best solution to the entire range of optimization problems [22]. Thus, a development of advanced metaheuristic algorithms, including a modification of existing ones, is an open research problem.

Metaheuristic algorithms are used to solve complex optimization problems in a wide range of fields including engineering, economics, information

Received November 1, 2018.

2010 Mathematics Subject Classification. 65K10; 49Q10; 93B40; 90C26.

Key words and phrases. Global optimization; finite element method; genetic algorithms; optimization of grillages; Fortran.

https://doi.org/10.12697/ACUTM.2019.23.20

Corresponding author: Darius Mačiūnas 
technology, etc. [1]. Many metaheuristic algorithms have been proposed: Artificial Bee Colony [8], Grasshopper Optimization Algorithm [17], Genetic Algorithm [2], Simulated Annealing Algorithm [2], Lion Optimization Algorithm [23], etc. Metaheuristic algorithms usually include: 1) a selection of an appropriate simulation of the problem; 2) evaluation of a quality of the solution applying a fitness function; 3 ) determination of operators in such a manner as to gain a new range of solutions.

The main goal of structural optimization is to obtain the best feasible layout of the structure securing minimum cost or minimum material consumption while satisfying appropriate requirements and constraints. Topology optimization seeks to secure the optimal scheme of a structure within a defined layout domain.

Engineering practice is one of the most important areas where optimization comes as a vital step in the optimal design of all structural parts of buildings. The optimal design of any structure should satisfy all requirements including the safety, comfort and reasonable price. Hereinafter the paper is focused on the optimal design of a particular type of foundations known as grillage-type foundations (further grillages).

Grillages are proven to be the most efficient structures in civil engineering and therefore broadly employed in the construction. The efficiency of grillages is extremely significant in the case of weak grounds. Any grillage is composed of inter-linked beams and supporting piles beneath. Piles are the ultimate structural elements of any building, distributing the loads rising from the building through the inter-linked beams. The inter-linked beams are built in situ, whilst reinforced concrete piles are normally produced at the factory, and therefore their dimensions are set during the design phase.

The optimal grillage should satisfy double-dealing criteria: 1) the amount of piles should be the least; 2) inter-linked beams should take on minimal feasible bending moments. Practically, these two separate optimization problems are competing rivals: 1) the search of the minimal amount of piles; 2) the search of the minimal volume of inter-linked beams.

Whilst the carrying strength of a separate pile is known, the first optimization problem might be introduced as a minimization of the maximum reactive force in piles within the entire set of piles. The second problem is adequate to the minimization of the maximum bending moment in the inter-linked beams. Moreover bending moments depend on the stiffness of the interlinked beams, hence the dimensions of a cross-section of the inter-linked beams have to be established simultaneously. Both optimization problems might be combined into one introducing a compromise objective function.

A comprehensive technical data on grillages can be found in $[6,15,3]$. The data regarding the idealizations on real grillages applied in the present mathematical model can be found in $[3,4]$. The corresponding initial data for the grillage optimization problem is listed as follows: 1) the loading data: 
active forces might be established as distributed trapezoidal loadings at any part of the beam, or as moments and concentrated loads at any point on the beam; 2) the material data of all beams (the material in one beam is considered to be isotropic); 3) the cross-sectional data of all beams (moments of inertia, the area);4) the geometrical scheme of inter-linked beams; 5) stiffness of a pile (rotational, vertical); 6) locations of fixed piles (if any); 7) the minimum feasible distance between adjacent piles; 8) the maximum allowable reactive force at any pile. The outcome of the optimization is the number of required piles and their location as well as cross-sectional dimensions of inter-linked beams.

The solution of this particular problem - specific placement of the given number of piles securing that reactive forces do not violate carrying capacities of the piles. If providing such a placement is not feasible, then the number of piles should be augmented. Hence the problem of the placement of piles might be formulated as the search for suitable pile positions beneath inter-linked beams. In a perfect grillage reactive forces are identical at all piles. In fact this is barely feasible, particularly in the case where a designer imposes the so-called "fixed supports" (normally in the corners of inter-linked beams) that must preserve their locations and are not permitted to switch locations during the optimization procedure.

Several technological restrictions might also make the perfect scheme of piles placement non obtainable, for instance the distance between adjacent piles should not be too short due to the particular capacities of a pile-driver. In the current paper fixed supports are not considered and a pile is permitted to take whatever location in the grillage, though normally piles are not placed at the joints of the grillage. This fact limits the pile placement problem coverage for a low-rise buildings excluding significant overturning moments due to a horizontal thrust, as for instance due to wind loads or the earthquake loading. An equivalent distribution of bending moments in inter-linked beams and an equivalent distribution of reactive forces among all piles specify the perfect grillage. Our know-how concerning the separate problems of the minimization of bending moments and reactive forces reveals that objective functions for a practical grillage optimization problems obtain many local minimum points. Another complex attribute of the problem is that normally objective functions are very sensitive to the location of piles: occasionally even a minor change of one position leads to a complete alteration of the value of the objective function. All together it makes the placement of piles in practical grillage a complex global optimization problem. 


\section{Previous works}

Since the beam optimization problems in the elaboration of optimal dimensioning of beams in grillage-type structures under a specified loading and boundary conditions (for instance [7] and references thereto) or optimal scheme of grillages (as per [16]) concentrated certain consideration, therefore the casual papers investigate the optimization problem of pile location schemes. The optimal pile location scheme beneath the raft is proposed [9] for minimization of the differential solution of the raft applying the genetic algorithm. In addition a three-dimensional finite element method program Plaxis 3D Foundation was utilized to establish the optimal pile spacing of Short Piled Raft foundation [19]. In [5] local search algorithms are utilized for optimal location of piles underneath an individual beam of the grillage and beneath the complete grillage employing the iterative algorithm [4]. Whilst the objective function obtains multiple local minimum points, the local search apparently is not a suitable alternative; consequently global optimization algorithms are on demand.

Since the deterministic global optimization exhibited practically inconceivable demand of computer resources for optimization of even small-scale practical grillages, the alternatives were explored. Encouraging outcome is demonstrated for typical grillages employing stochastic algorithms, among which the genetic algorithm and the simulated annealing algorithm outperformed other algorithms [2]. The modified genetic algorithm including special phenotypes' selection and crossover operators involving default elaborated principles is introduced [14] hereby rejecting the random crossover. In $[2,14]$ the routine - for verification of constraints and for computation of the objective function - is linked to the optimization algorithm as the "black-box" program.

Furthermore, the problem of optimal piles placement scheme was resolved utilizing the several dimension optimization method Bacoor [13]. The method demonstrated much better results compared to all other algorithms concerning grillage optimization, especially when piles must be positioned at very irregular intervals. Classical stochastic algorithms outperformed the other algorithms in the case when more regular allocation of piles is expected.

In every single occasion the genetic algorithm (GA) in tandem with attentively combined genetic parameters secured significantly better results compared to other algorithms. Amongst such parameters, the mutation operator has a significant contribution $[24,20]$ to introduce potentially beneficial changes to the upcoming generation. Hence, in this study, the main attention is focused to the mutation operator. The mutation was analysed, e.g., in [21] where random-mutation-based search technique was incorporated and mutation vector was generated by fusion of host design variables and randomly generated variables. In addition the present study extends our 
previous works with two main aspects. First, we introduce two advanced metaheuristics: advanced genetic algorithm with parallel strategy and advanced adaptive genetic algorithm. Second, we propose the synergy of two newly introduced advanced metaheuristics.

Hereinafter we define the optimization problem formulation, the algorithm, and present numerical results of optimization of several practical grillages which were optimized earlier $[2,11,13]$. The results demonstrate the advantages of newly introduced advanced metaheuristics.

\section{Problem formulation and optimization algorithm}

Hence, problem formulation - layout scheme of piles searching for an appropriate pile placement underneath the inter-linked beams. A uniform distribution of bending moments in beams and uniform distribution of reactive forces among all piles would represent the case of an ideal grillage.

The solution of such problems is normally not a single optimal objective function value but an array of compromise solutions, the so-called Paretooptimal solutions. Every Pareto solution is optimal, i.e., no improvement might be attained in one objective component without degrading at least one of the rest of objective components. Hence, the primary aim of the multiobjective optimization is to detect several Pareto-optimal solutions in order to show the compromise information amongst the competing objectives.

The simplest multi-objective optimization approach is the weighting method. The method has a potentiality in such a situation when the projection of the possible design space into the objective space is convex. Deliberating an optimization problem including two objectives $T_{1}(x)$ and $T_{2}(x)$ with weighting coefficients $z_{1}$ and $z_{2}$ respectively, the multi-objective problem can be treated as the following single objective optimization problem:

$$
T^{*}=\min _{x \in D} T(x)=T_{1}(x) \cdot z_{1}+T_{2}(x) \cdot z_{2} .
$$

Here $T(x)$ is a non-linear objective function of continuous variables $T: \Re^{n} \rightarrow$ $\Re, n$ is the number of design parameters $x$ defining positions of piles and dimensions of a cross-section of inter-linked beams, $D \subset \Re^{n}$ is a feasible region of design parameters. Besides the global minimum $T^{*}$ one or all global minimizers $x^{*}: T\left(x^{*}\right)=T^{*}$ should be found. No assumptions on unimodality are involved into the formulation of the problem - many local minima might exist. If $D$ is convex, then the solution of (1) is optimal for the indicated values of $z_{1}$ and $z_{2}$. For distinct values of coefficients $z_{1}$ and $z_{2}$ many optimal solutions might be generated. The best trade-off solution might be chosen on the basis of compromise considerations.

In this study the maximum vertical reactive force at a pile (2) and the maximal bending moment in the inter-connected beams (3) are introduced 
as the first and the second elements of the objective function (1) correspondingly:

$$
\begin{gathered}
T_{1}(x)=\max _{i=1, \ldots, N_{p}} R_{i}(x), \\
T_{2}(x)=\max _{i=1, \ldots, N_{b} \cdot s} M_{i}(x) .
\end{gathered}
$$

Here $N_{p}$ - the number of piles, $R_{i}(x)$ - the reactive force at the $i$-th pile, $N_{b}$ - the number of beams, $s$ - the number of segments in one beam, where the calculation of bending moments $M_{i}(x)$ is executed; normally three points are enough to "capture" the near-maximal value of bending moment lengthwise the beam [11]. The set of design parameters are established of positions of all piles $x_{i}, i=1, \ldots, N_{p}$ including the cross-sectional dimensions of beams: height $h_{c s}$ and width $b_{c s}$. Dimensions $h_{c s}$ and $b_{c s}$ are presumed to be equivalent among all beams in the grillage.

3.1. Constraints. Whilst supporting piles may be located only beneath inter-linked beams, consequently, the following constraint has to be applied: the piles can change their position entirely along inter-linked beams during the optimization routine. Hence, a two-dimensional beam structure of the grillage is "unfolded" to a one-dimensional composition, and piles are permitted to move through this space freely. The optimization routine yields the distribution of piles in the space and the backward transformation restores the locations of piles into the two-dimensional beam composition of the grillage. The constraints for the design parameters are established as

$$
0 \leq x_{i} \leq L_{t o t}, \quad i=1, \ldots, N_{p},
$$

where $x_{i}$ is a design parameter indicating the position of the $i$-th pile, and $L_{t o t}$ is the entire length of all beams in the grillage.

Provided the minimal feasible distance between adjacent piles is defined, there are supplementary constraints introduced:

$$
\left\|x_{i}-x_{k}\right\| \geq \beta, \quad i \neq k,
$$

where $x_{i}$ and $x_{k}$ are one-dimensional coordinates of piles and $\left\|x_{i}-x_{k}\right\|$ indicates the distance between the closest piles; $\beta$ depends on the technical characteristics of a pile-driver machine, $k=1, \ldots, N_{p}$. For the implementation of this constraint a penalty is included in the objective function. Normally strength constraints must be verified for all beams in the grillage. While the maximal bending moment $M_{\max }$ is calculated during the optimization routine and the dimensions of cross-section of all inter-linked beams are equivalent, the sole verification is enough:

$$
M_{\text {max }} \leq M_{\text {allow }},
$$

where $M_{\text {allow }}$ is dependent on allowable stresses in a concrete and a reinforcement, dimensions of the beam cross-section and a reinforcement area. Consequently, the constraint enlarges the height $h_{c s}$ and reduces the width 
$b_{c s}$ of the beam cross-section. Hence, a complementary constraint must be included in the dimensions of the beam cross-section:

$$
\frac{h_{c s}}{b_{c s}} \leq\left(\frac{h_{c s}}{b_{c s}}\right)_{\max }
$$

where height $h_{c s}$ and width $b_{c s}$ are ranging in the given intervals:

$$
h_{c s} \in\left[h_{c s_{M I N}} ; h_{c s_{M A X}}\right], \quad b_{c s} \in\left[b_{c s_{M I N}} ; b_{c s_{M A X}}\right], \quad h_{c s} \geq b_{c s} .
$$

The allowable ratio of cross-sectional dimensions (i.e., $\left(h_{c s} / b_{c s}\right)_{\max }=3$ ) and limitations for cross-sectional beam dimensions $\left(b_{c s} \in[0.1 ; 0.9], h_{c s} \in\right.$ $[0.1 ; 0.9])$ ensure that the local buckling conditions of a beam are satisfied $[5,12]$. The lateral-torsional buckling for the grillages is not relevant.

3.2. Direct problem. A direct problem is interpreted as the computation of bending moments and reactive forces in the grillage. The direct problem is solved employing a finite element (FE) program. The FE program is incorporated into the optimization program as a "black-box" routine. The successive idealizations are included for the grillage in the direct problem: piles are interpreted as supports, i.e., as finite element mesh nodes with specified elastic boundary conditions, whilst inter-linked beams - as bending beam finite elements. The optimization speed significantly depends on the time of the solution of the direct problem. Hence, originally, problem-oriented and fast FORTRAN programs including a particular mesh pre-processor have been built and utilized. Beam elements have two nodes including six degrees of freedom at each node (three displacements along the local coordinate axes and three rotations about these axes). The stiffness matrix $[\mathrm{K}]$ of an element is available in plenty of textbooks, as for instance [25]. Stability constraints of the structure are ensured introducing the main equation of statics:

$$
[K]^{a}\{u\}^{a}=\{F\}^{a},
$$

here $\{u\}$ - nodal displacements, $\{F\}$ - active forces, $a$ - an ensemble of elements (not specified further in equations). Whereas nodal displacements $u_{j}$ and $u_{i}$ are obtained, reactive forces $R_{i}$ at piles and bending moments $M$ in beams may be computed as follows:

$$
R_{i}=\sum\left[K_{i j}\right] u_{j}, \quad M=E I_{z} \kappa, \quad \kappa=-\frac{d^{2}}{d x^{2}}\left(\sum_{i} N_{i} u_{i}\right),
$$

where $I_{z}$ - the second moment of inertia, $\kappa$ - the beam curvature, $E$ Young's modulus, $N_{i}$ - the second-order Hermitian interpolation functions, $u_{i}$ - nodal displacements of the finite element. 
3.3. Optimization algorithm. GA - a stochastic global optimization algorithm simulating laws of the evolution of the nature involving selection, crossover and mutation steps. Every individual of the initial population is the entire finite element model of a grillage and fulfils the requirements of constraints (4), (5), and (7). Hereinafter population size (PS) individuals of the initial population are generated applying modified random search routine. Thus, design parameters are generated randomly with uniform scattering, though complementary constraint is introduced for the parameters specifying the pile location $x$ : the difference between two decision variables $x_{i}$ and $x_{k}$ must be larger than or equivalent to $V$ :

$$
\left\{\begin{array}{l}
\left|x_{i}-x_{k}\right| \geq V, \quad i \neq k, \\
V=\frac{L_{t o t}}{2 N_{p}},
\end{array}\right.
$$

where $V$ is obtained dividing the half of the total length $L_{t o t}$ of all beams by the number of piles $N_{p}$.

Provided the constraints (4), (5), (7), (8) are violated, the structure is assumed to be non-feasible. The suggested heuristic alteration is reasoned by the circumstance that due to the normal distribution of loading over grillage beams, piles should be allocated over the entire space of the grillage as well. Thus the quality of the initial population is significantly improved and eventually it secures a remarkably better outcome of evolution [2]. Bending moments in beams and reactive forces at piles are computed for generating feasible individuals. The individual with the minimal value of the objective function (1) is assumed to be the best solution available. Hence, real numbers are utilized for coding of individuals. Thus, the individual is encoded as a line of a sequence of real numbers, i.e. the position of piles in a one-dimensional construct and cross-sectional dimensions of the beam. Several examples of individuals can be found in our prior papers $[12,11]$.

The roulette principle is utilized for the selection of individuals: half pairs of individuals are selected for breeding. The smaller objective function value of individuals is secured, the higher probability those individuals possess to be selected. The selection probability $P$ of the $i$-th individual with the objective function value $T_{i}$ can be defined as

$$
P_{i}=\left(T_{i} \sum_{j} \frac{1}{T_{j}}\right)^{-1},
$$

where the sum operator $\sum$ includes the whole population.

The crossover routine between two individuals (selected for breeding) is executed with a probability $p_{-}$crossover and the location of the crossover is derived randomly from the interval $\left[1, N_{p+1}\right]$.

Some examples of the crossover of two individuals can be found in our prior works $[12,11]$. 
The mutation routine is executed with probability p_mutation for every decision variable separately. Every single value is altered by a random number evenly distributed over $\left[-x_{1} ; x_{1}\right]$ (here $x_{1} \approx L_{t o t} / 100$ for design parameters specifying the pile location), and by a random number evenly distributed over $\left[-x_{2} ; x_{2}\right]$ (here $x_{2} \approx h_{c_{M I N}} / 10$ for the height $h_{c s}$ of the beam cross-section, or $x_{2} \approx b_{c s_{M I N}} / 10$ for the width $b_{c s}$ of the beam cross-section; $\left.h_{c s_{M I N}}=b_{c s_{M I N}}=0.1\right)$.

Values of $p_{\text {_crossover }}$ and $p_{-}$mutation are carefully tuned on the basis of numerical experiments. In the course of the crossover and mutation routines the individuals, contravening constraints (5) and (6), might be generated. Such non-feasible individuals are penalized and consequently rejected. The algorithm proceeds for the specified number of generations; normally several hundreds of populations secure the converged solution.

Though, normally the genetic algorithm (GA) exhibits fast convergence at the beginning of the solution and slow convergence after a specific number of generated populations. Thus, modifications of the classical GA have been proposed: genetic algorithm with distributed strategy (GADS) [12] and adaptive genetic algorithm (AGA) [11]. GADS and AGA were introduced to avoid a local solution point and to get an opportunity for searching a broader territory of the design space. GADS has yielded in average $5 \%$ better results (i.e., lower values of the objective function (1)) than the classical GA; meanwhile AGA has yielded in average $3 \%$ better results (i.e., lower values of the objective function (1)) than the classical GA [10].

The current paper proposes the synergy of two advanced metaheuristics: 1) advanced genetic algorithm with distributed strategy (AGADS), 2) advanced adaptive genetic algorithm (AAGA). AGADS includes the genetic algorithm with distributed strategy (GADS) [12] introducing a modified selection procedure, while AAGA involves the adaptive genetic algorithm (AGA) [11] introducing a modified adaptation procedure.

The suggested new optimization algorithm operates AGADS and AAGA in the following sequence of two stages: 1) AGADS STAGE. Three autonomous and separate optimization routines are initiated simultaneously and proceed until the point, where slowing of convergence prevails. At this particular moment the predefined number of individuals (with the highest objective function values) is selected from each of the three initiated optimization routines and the new population is established. Novelty: the predefined number of individuals is not randomly selected and rather is selected based on the score of the objective function. 2) AAGA STAGE. Further optimization of the new population (obtained in AGADS STAGE) is launched implementing AAGA. AAGA has two main points. First of all, the moment of time when the advanced adaptation of an algorithm is needed must be determined. Secondly, the advanced adaptive population size operator (AAPSO) and the advanced adaptive mutation operator (AAMO), 
depending on the obtained convergence level, should be introduced. The moment of time for the launching of adaptation is determined by measuring the convergence rate of the best solution in the population.

\section{Numerical application: experiments and results}

The previously described new optimization algorithm (involving the synergy of AGADS and AAGA) has been applied to optimize the pile placement schemes and dimensions of beams' cross-section of several practical grillages. Data for the solution of such problems, including from 10 to 55 design parameters, are received from several Dutch design bureaus (courtesy of Consultancy W. F. O. B.V., Paauw B.V. Aannemingsbedrijf and others) - they use the professional software package for structural engineering MatrixFrame ( http://www.matrix-software.com/uk/structuralengineering/matrixframe/ index.html). It is intended for analysis of steel and concrete erections.

Our original software, for the single-objective optimization of pile placement schemes applying local search methods, is realized in MatrixFrame software package [5]. First of all this paper presents solution approach of two simplest grillages with different topologies (Appendix, Figures 1 and 2). With reference to the loading cases minimum 10 and 15 piles are required for such grillages, respectively. The described grillages were analysed in our prior studies $[12,2,11]$ utilizing classical GA, AGA and GADS. Secondly, the optimization results of 17-pile and 18-pile grillages (Appendix, Figures 6,7 , and 8) are provided. These grillages also were the object of our prior research $[14,13]$, though only pile placement optimization problem was implemented.

4.1. Benchmark: optimization of 10-pile and 15-pile grillages. The results of optimization of the two simplest grillages (10-pile grillage and 15-pile grillage) (Appendix, Figures 1 and 2) applying a new optimization algorithm are demonstrated as a benchmark.

The simple method of weighting coefficients [6] for multi-objective optimization is valid ultimately in the case of the convexity of the feasible design space. Therefore the shape of the objective function domain has been explored and verified that the feasible design space is convex by the side where the optimal solution is expected and as a result all possible Pareto solutions might be discovered $[12,11]$.

Numerical experiments on optimization of 10-pile and 15-pile grillages were executed to determine optimum pile placement scheme and cross-sectional dimensions of beams applying the new optimization algorithm. Based on numerical experiments in genetic parameters were carefully tuned to obtain the relevant values of GA parameters for: 1) AGA [11], 2) GADS [12], 3) AAGA and AGADS (Table 1). 


\begin{tabular}{|c|c|c|}
\hline Name & Value & Value \\
\hline Grillage type & 10 -pile & 15 -pile \\
\hline Probability of crossover & $60 \%$ & $60 \%$ \\
\hline Probability of mutation & $10 \%$ & $10 \%$ \\
\hline Population size & 48 individuals & 48 individuals \\
\hline
\end{tabular}

TABLE 1. Values of genetic parameters for 10-pile and 15-pile grillages for AAGA and AGADS.

The most acceptable ratio of cross-sectional dimensions $\left(\left(h_{c s} / b_{c s}\right)_{\max }=3\right)$ and limitations for cross-sectional beam dimensions $\left(b_{c s} \in[0.1 ; 0.9], h_{c s} \in\right.$ $[0.1 ; 0.9])$ were described in $[5,12]$.

The advanced metaheuristic operates AGADS and AAGA in the following sequence of two stages: 1) AGADS STAGE. Three autonomous and separate optimization routines are initiated simultaneously and proceed to the point, where slowing of convergence prevails (in our consideration when the gain in the objective function magnitude among 10 generations in a row is below 10\%; though in our prior study [12] it was set to below $5 \%$ and now, in our opinion, this $10 \%$ increase should give the impulse for a faster convergence). At this particular moment of time 16 individuals (with the highest objective function values) are selected from each of three initiated optimization routines and the new population, containing 48 selected individuals, is established; Novelty: 16 individuals from each optimization routine are not randomly selected and rather are selected based on the score of the objective function. 2) AAGA STAGE. Further optimization (with 48 individuals obtained in AGADS STAGE) is launched implementing AAGA. AAGA has two main points. First of all, the moment of the time when the advanced adaptation of an algorithm is needed must be determined. Secondly, the advanced adaptive population size operator (AAPSO) and the advanced adaptive mutation operator (AAMO), depending on the obtained convergence level, should be introduced. The moment of the time for the launching of the adaptation is determined by measuring the convergence rate of the best solution in the population. It is suggested to launch the adaptation when the gain in the objective function value (GOFV) between 10 generations in a row is less than $10 \%$. Since convergence of AAGA has tendency to slow down over the certain number of generations, a range of GOFV is introduced (Table 2). Depending on the range of GOFV the following advanced adaptive population size operator (AAPSO) (9) and the advanced adaptive mutation operator (AAMO) (11) are suggested:

$$
A A P S O=P S \cdot M U L T I P L I E R \_1
$$


with a constraint

$$
A A P S O \geq 10
$$

and

$$
A A M O=P M \cdot M U L T I P L I E R \_2
$$

with a constraint

$$
A A M O \leq 100,
$$

here $P S$ - population size, $P M$ - probability of mutation, value of $M U L T I$ PLIER_1 and MULTIPLIER_2 depend on the corresponding value of GOFV (Table 2).

\begin{tabular}{|c|c|c|}
\hline Range of $G O F V, \%$ & MULTIPLIER_1 & MULTIPLIER_2 \\
\hline $9.99-9.00$ & 0.95 & 1.95 \\
\hline $8.99-8.00$ & 0.90 & 1.90 \\
\hline $7.99-7.00$ & 0.85 & 1.85 \\
\hline $6.99-6.00$ & 0.80 & 1.80 \\
\hline $5.99-5.00$ & 0.75 & 1.75 \\
\hline $4.99-4.00$ & 0.70 & 1.70 \\
\hline $3.99-3.00$ & 0.65 & 1.65 \\
\hline Less than 3.00 & 0.60 & 1.60 \\
\hline
\end{tabular}

TABLE 2. Values of GOFV, MULTIPLIER_1, and MULTIPLIER_2.

Termination condition of AAGA STAGE: when at least one of the constraints (10) and (12) is violated. Since genetic algorithms are stochastic algorithms, both grillages were optimized 30 times employing obtained genetic parameters in order to obtain acceptable scatter of results (Table 3).

The results show the algorithm with integrated AGADS and AAGA outperformed: 1 ) the AGA by $6.89 \%$ and $6.24 \%$ for 10 -pile and 15 -pile grillages correspondingly; and 2) GADS by $11.30 \%$ and $15.97 \%$ for 10 -pile and 15 pile grillages correspondingly. Such results indicate that the suggested new optimization algorithm (with integrated AGADS and AAGA) might be successfully applied for optimization not only for 10-pile and 15-pile grillages, but also for more complex grillages.

4.2. Optimization of complex grillages. The same optimization routines (AGA, GADS, integrated AAGA and AGADS) have been applied to solve the problem with several complex grillages (17-pile grillage and 18-pile grillage) (Appendix, Figures 6, 7 and 8). Based on numerical experiments genetic parameters were carefully tuned to obtain the relevant values of GA parameters for both of these two complex grillages: 1) AGA, 2) GADS, 3) AAGA and AGADS (Table 4). 


\begin{tabular}{|c|c|c|c|c|c|c|}
\hline $\begin{array}{l}\text { Algorithm/ } \\
\text { Name }\end{array}$ & \multicolumn{2}{|c|}{ AGA [11] } & \multicolumn{2}{|c|}{ GADS [12] } & \multicolumn{2}{|c|}{$\begin{array}{c}\text { Integrated AGADS } \\
\text { and AAGA }\end{array}$} \\
\hline Grillage type & 10-pile & 15 -pile & 10-pile & 15-pile & 10-pile & 15-pile \\
\hline Generation & 100 & 100 & 100 & 100 & 100 & 100 \\
\hline $\begin{array}{l}\text { Runs of } \\
\text { algorithm }\end{array}$ & 30 & 30 & 30 & 30 & 30 & 30 \\
\hline $\begin{array}{l}\text { The best } \\
\text { value of } \\
\text { the objective } \\
\text { function }\end{array}$ & 96.07 & 78.68 & 100.04 & 85.84 & 89.88 & 74.02 \\
\hline $\begin{array}{l}\text { Relative } \\
\text { standard } \\
\text { deviation } \\
\text { of results, \% }\end{array}$ & 1.07 & 1.88 & 3.87 & 4.02 & 2.11 & 2.83 \\
\hline $\begin{array}{c}\text { Optimal } \\
\text { cross-sectional } \\
\text { dimensions of } \\
\\
h_{c s} \\
\text { beam: } \quad \times \\
b_{c s}\end{array}$ & $\begin{array}{c}0.58 \\
\times \\
0.20\end{array}$ & $\begin{array}{c}0.69 \\
\times \\
0.24\end{array}$ & $\begin{array}{c}0.63 \\
\times \\
0.22\end{array}$ & $\begin{array}{c}0.38 \\
\times \\
0.13\end{array}$ & $\begin{array}{c}0.72 \\
\times \\
0.25\end{array}$ & $\begin{array}{c}0.78 \\
\times \\
0.27\end{array}$ \\
\hline $\begin{array}{l}\text { Value of actual } \\
\text { ratio: } h_{c s} / b_{c s}\end{array}$ & 2.90 & $\sim 2.86$ & $\sim 2.86$ & $\sim 2.92$ & $\sim 2.94$ & $\sim 2.91$ \\
\hline
\end{tabular}

TABLE 3. Comparison of optimization results for 10-pile and 15-pile grillages.

\begin{tabular}{|c|c|c|}
\hline Name & Value & Value \\
\hline Grillage type & $17-$ pile & 18 -pile \\
\hline Probability of crossover & $55 \%$ & $55 \%$ \\
\hline Probability of mutation & $10 \%$ & $10 \%$ \\
\hline Population size & 48 individuals & 48 individuals \\
\hline
\end{tabular}

TABLE 4. Values of genetic parameters for 17-pile and 18-pile grillages for AGA, AAGA, GADS, and AGADS.

Both 17-pile and 18-pile grillages were optimized 30 times employing obtained genetic parameters in order to obtain the acceptable scatter of results (Table 5).

The results show that the algorithm with integrated AGADS and AAGA outperformed: 1) the AGA by $6.70 \%$ and $4.86 \%$ for 17 -pile and 18-pile grillages correspondingly; and 2) GADS by $10.32 \%$ and $12.73 \%$ for 17 -pile and 


\begin{tabular}{|c|c|c|c|c|c|c|}
\hline $\begin{array}{l}\text { Algorithm/ } \\
\text { Name }\end{array}$ & \multicolumn{2}{|c|}{ AGA [11] } & \multicolumn{2}{|c|}{ GADS [12] } & \multicolumn{2}{|c|}{$\begin{array}{c}\text { Integrated AGADS } \\
\text { and AAGA }\end{array}$} \\
\hline Grillage type & 17-pile & 18-pile & 17-pile & 18-pile & 17-pile & 18-pile \\
\hline Generation & 100 & 100 & 100 & 100 & 100 & 100 \\
\hline $\begin{array}{l}\text { Runs of } \\
\text { algorithm }\end{array}$ & 30 & 30 & 30 & 30 & 30 & 30 \\
\hline $\begin{array}{l}\text { The best } \\
\text { value of } \\
\text { the objective } \\
\text { function }\end{array}$ & 201.21 & 97.35 & 208.04 & 104.66 & 188.57 & 92.84 \\
\hline $\begin{array}{l}\text { Relative } \\
\text { standard } \\
\text { deviation } \\
\text { of results, \% }\end{array}$ & 1.68 & 1.97 & 3.11 & 4.26 & 1.89 & 2.54 \\
\hline $\begin{array}{c}\text { Optimal } \\
\text { cross-sectional } \\
\text { dimensions of } \\
h_{c s} \\
\text { beam: } \times \\
b_{c s}\end{array}$ & $\begin{array}{c}0.81 \\
\times \\
0.30\end{array}$ & $\begin{array}{c}0.57 \\
\times \\
0.22\end{array}$ & $\begin{array}{c}0.73 \\
\times \\
0.26\end{array}$ & $\begin{array}{c}0.69 \\
\times \\
0.24\end{array}$ & $\begin{array}{c}0.78 \\
\times \\
0.27\end{array}$ & $\begin{array}{c}0.44 \\
\times \\
0.16\end{array}$ \\
\hline $\begin{array}{l}\text { Value of actual } \\
\text { ratio: } h_{c s} / b_{c s}\end{array}$ & 2.75 & $\sim 2.62$ & $\sim 2.81$ & $\sim 2.88$ & $\sim 2.91$ & $\sim 2.83$ \\
\hline
\end{tabular}

TABLE 5. Comparison of optimization results for 17-pile and 18-pile grillages.

18-pile grillages correspondingly. Such results indicate that the suggested new optimization algorithm (with integrated AGADS and AAGA) might demonstrate successful solutions for optimization complex grillages including 17-pile and 18-pile grillages.

Numerical results have revealed the reasonable capabilities of the introduced new optimization algorithm: the integrated AGADS and AAGA. The corresponding pile placement schemes are available in the Appendix.

\section{Conclusions}

(1) The proposed two advanced metaheuritics - AAGA and AGADS - were introduced with certain modifications comparing to former AGA and GADS. AGA was introduced with superior cross-over and mutation operators, while GADS has experienced a certain improvement in selection routine. In addition, the integration of AAGA and AGADS was suggested and implemented. 
(2) The calculation method for simultaneous topology and size optimization of grillages applying the synergy of introduced metaheuristics AAGA and AGADS is proposed and realized.

(3) Algorithm with integrated AAGA and AGADS has yielded on average $6.17 \%$ better results (i.e., lower values of the objective function) than former AGA.

(4) Algorithm with integrated AAGA and AGADS has yielded on average $12.58 \%$ better results (i.e., lower values of the objective function) than former GADS.

(5) Hence, the introduced method - algorithm with integrated AAGA and AGADS - might be assumed as a new global optimization algorithm securing better results.

\section{Appendix}

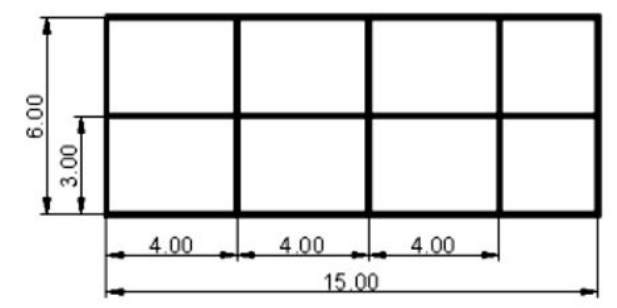

FiguRE 1. 10-pile grillage: topology.

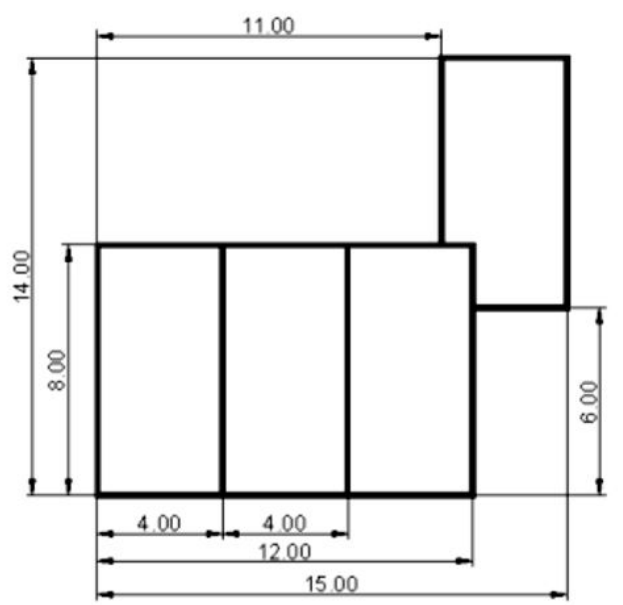

FIGURE 2. 15-pile grillage: topology. 


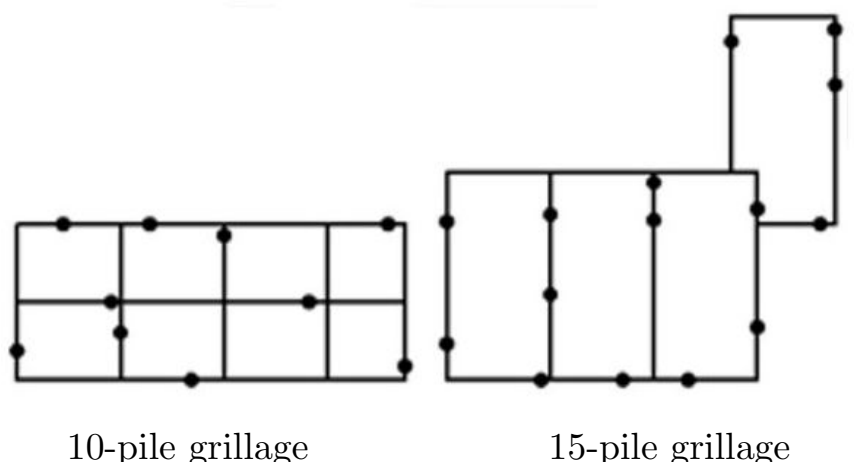

Figure 3. Optimal pile placement scheme utilizing AGA.

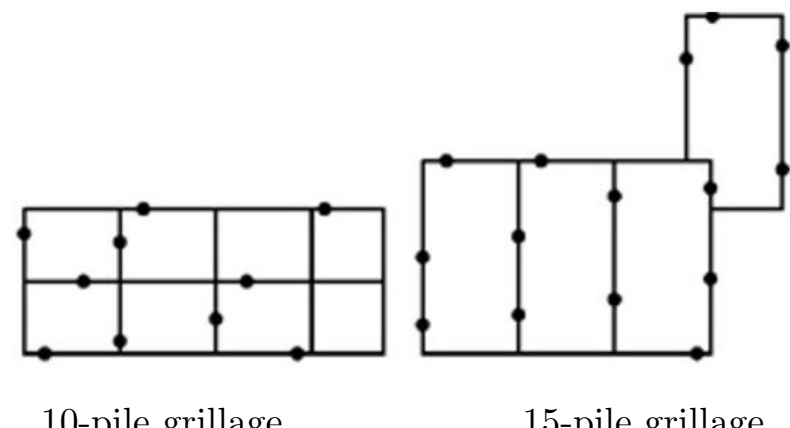

Figure 4. Optimal pile placement scheme utilizing GADS.

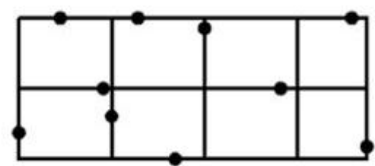

10-pile grillage

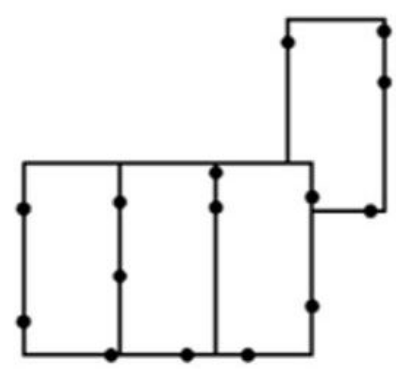

15-pile grillage

FIGURE 5. Optimal pile placement scheme utilizing synergy of AAGA and AGADS. 


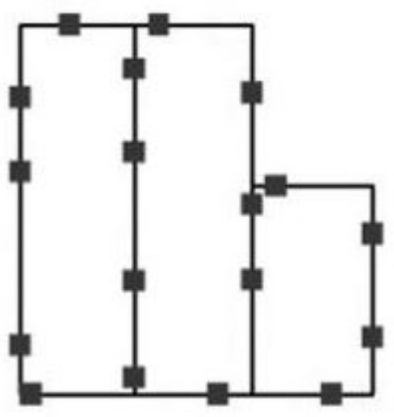

18-pile grillage

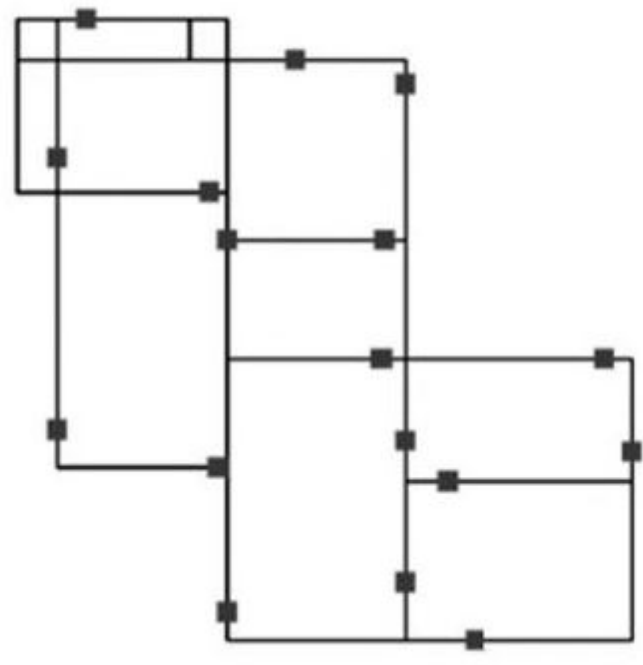

17-pile grillage

Figure 6. Optimal pile placement scheme utilizing AGA.

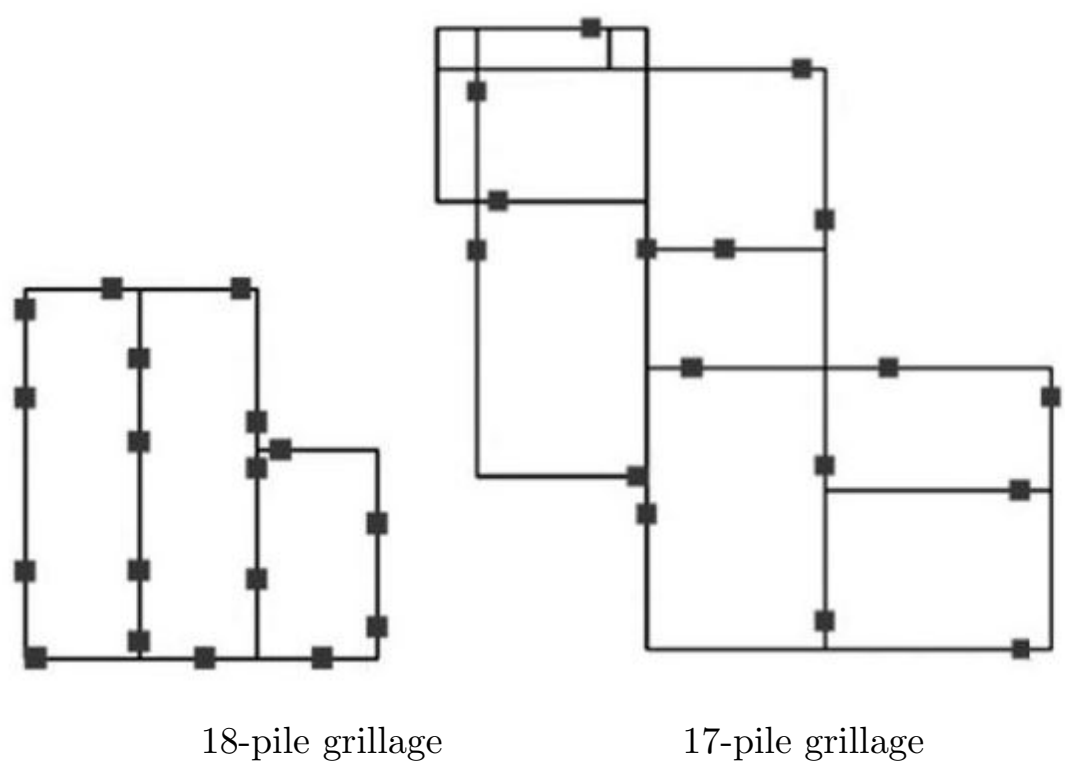

Figure 7. Optimal pile placement scheme utilizing GADS. 


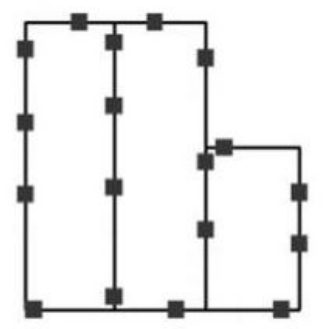

18-pile grillage

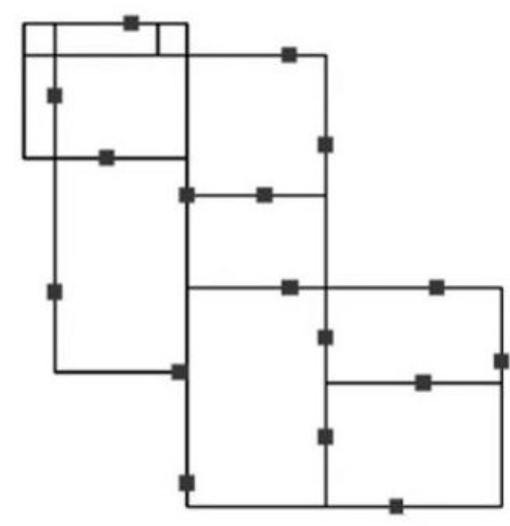

17-pile grillage

Figure 8. Optimal pile placement scheme utilizing synergy of AAGA and AGADS.

Acknowledgement. The authors are grateful to the referees for their valuable suggestions and remarks that definitely improved the paper.

\section{References}

[1] E. F. Alzaghoul and S. N. Fakhouri, Collaborative strategy for grey wolf optimization algorithm, Modern Appl. Sci. 12(7) (2018), 73-88.

[2] R. Belevičius, S. Ivanikovas, D. Šešok, S. Valentinavičius, and J. Žilinskas, Optimal placement of piles in real grillages: experimental comparison of optimization algorithms, Inf. Tech. Control 40(2) (2011), 123-132.

[3] R. Belevičius and S. Valentinavičius, Optimisation of grillage-type foundations, J. Civ. Eng. Manag. 6(6) (2000), 255-261.

[4] R. Belevičius, S. Valentinavičius, and E. Michnevič, Multilevel optimization of grillages, J. Civ. Eng. Manag. 2(8) (2002), 98-103.

[5] R. Belevičius, S. Valentinavičius, and R. J. Weener, Optimisation of grillage-type foundations, in: Proceedings of 2nd Worldwide ECCE Symposium Information and Communication Technology in the Practice of Building and Civil Engineering, Helsinki, 2001, pp. 251-256.

[6] J. E. Bowles, Foundation Analysis and Design, 5th Edition, McGraw-Hill International, Singapore, 2017.

[7] D. Chamoret, K. Qiu, N. Labed, and M. Domaszewski, Optimization of truss and grillage structures by non-deterministic method, in: Proceedings of 9th International Conference on Computational Structures Technology, Stirlingshire, 2008, Paper 51.

[8] D. Karaboga and B. Basturk, A powerful and efficient algorithm for numerical function optimization: artificial bee colony $(A B C)$ algorithm, J. Global Optim. 39(3) (2007), 459-471.

[9] K. N. Kim, S. H. Lee, K. S. Kim, C. K. Chung, M. M. Kim, and H. S. Lee, Optimal pile arrangement for minimizing differential settlements in piled raft foundations, Comput. Geotechn. 28(4) (2001), 235-253. 
[10] D. Mačiūnas, Multi-objective Global Optimization of Grillages Using Genetic Algorithms, PhD Thesis, VGTU Press Technika, Vilnius, 2013. (Lithuanian)

[11] D. Mačiūnas and R. Belevičius, Multi-objective optimization of grillages using adaptive genetic algorithm, Int. Rev. Mech. Eng. 6(3) (2012), 432-439.

[12] D. Mačiūnas, R. Belevičius, and D. Šešok, Multi-objective optimization of grillages using genetic algorithm with parallel strategy, in: Proceedings of the 1st Virtual International Conference on Advanced Research in Scientific Area (2012), pp. 1842-1848.

[13] J. Mockus, R. Belevičius, D. Šešok, J. Kaunas, and D. Mačiūnas, On Bayesian approach to grillage optimization, Inf. Tech. Control 41(4) (2012), 332-339.

[14] M. Ramanauskas, D. Šešok, R. Belevičius, J. Kurilov, and S. Valentinavičius, Genetic algorithm with modified crossover for grillage optimization, Int. J. Comput. Commun. Control 12(3) (2017), 393-402.

[15] L. C. Reese, W. M. Isenhower, and S. T. Wang, Analysis and Design of Shallow and Deep Foundations, John Wiley and Sons, New Jersey, 2006.

[16] G. I. N. Rozvany, Exact optimal layout of grillages for partially upward and partially downward loading, Struct. Multidiscip. Optim. 4(13) (1997), 267-270.

[17] S. Saremi, S. Mirjalili, and A. Lewis, Grasshopper optimisation algorithm: theory and application, Adv. Eng. Softw. 105 (2017), 30-47.

[18] N. Siddique and H. Adeli, Nature inspired computing: an overview and some future directions, Cogn. Comput. 7(6) (2015), 706-714.

[19] S. M. Suro, I. Bakar, and A. Sulaeman, Pile spacing optimization of short piled raft foundation system for obtaining minimum settlement on peat, IOP Conference Series: Materials Science and Engineering 136 (2016), 1-7.

[20] G. G. Tejani, Investigation of Aadvanced Mmetaheuristic Techniques for Simultaneous Size, Shape, and Topology Optimization of Truss Structures, PhD Thesis, Pandit Deendayal Petroleum University, India, 2017.

[21] G. G. Tejani, V. J. Savsani, V. K. Patel, and P. V. Savsani, Size, shape, and topology optimization of planar and space trusses using mutation-based improved metaheuristics, J. Comput. Des. Eng. 5(2) (2018), 198-214.

[22] D. H. Wolpert and W. G. Macready, No free lunch theorems for optimization, IEEE Trans. Evol. Comput. 1(1) (1997), 67-82.

[23] M. Yazdani and F. Jolai, Lion optimization algorithm (LOA): a nature-inspired metaheuristic algorithm, J. Comput. Des. Eng. 3(1) (2016), 24-36.

[24] Y. Zhang and C. Mueller, Shear wall layout optimization for conceptual design of tall buildings, Eng. Struct. 140 (2017), 1-31.

[25] O. C. Zienkiewicz and R. L. Taylor, The Finite Element Method for Solid and Structural Mechanics, 7th Edition, Elsevier Butterworth-Heinemann, London, 2013.

Department of Information Technologies, Faculty of Fundamental Sciences,

Vilnius Gediminas Technical University, LT-10223 Vilnius, Lithuania

E-mail address: rimantas.belevicius@vgtu.lt

Department of Applied Mechanics, Faculty of Civil Engineering, Vilnius

Gediminas Technical University, LT-10223 Vilnius, Lithuania

E-mail address: darius.maciunas@vgtu.1t

Department of Information Technologies, Faculty of Fundamental Sciences, Vilnius Gediminas Technical University, LT-10223 Vilnius, Lithuania

E-mail address: dmitrij.sesok@vgtu.lt 